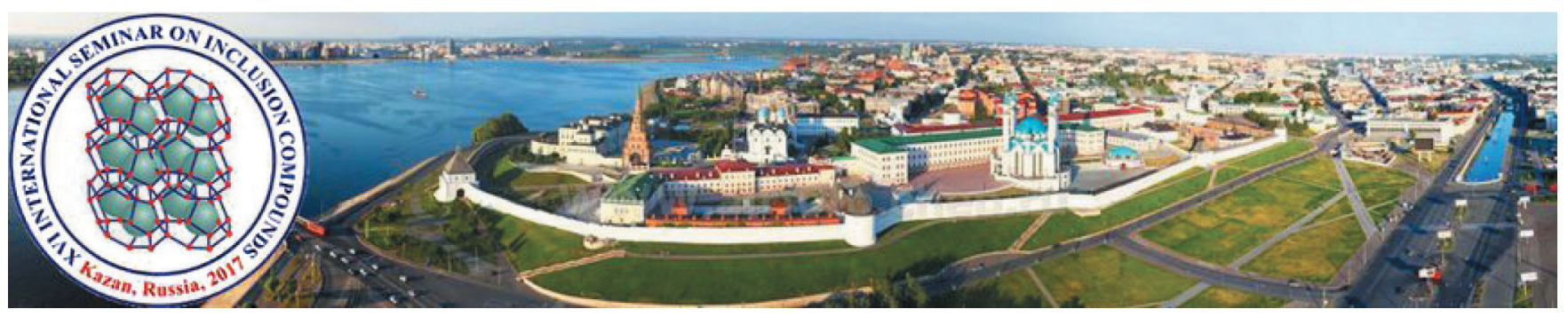

DOI: $10.6060 / \mathrm{mhc} 170133 \mathrm{~s}$

\title{
History of ISIC Conferences
}

\author{
Janusz Lipkowski, Kinga Suwinska ${ }^{\circledR}$ \\ Cardinal Stefan Wyszynski University in Warsaw, Warsaw, 01-938 Poland \\ ${ }^{\circledR}$ Corresponding author E-mail: k.suwinska@uksw.edu.pl
}

This biennial conference series dates back to 1981 . It was initiated during the "Cold War" as an interactive forum for exchanges between scientists from Eastern Bloc countries and those from the West. Since the end of the Cold War the conference has attracted increasing international interest, but has continued to be hosted exclusively in former Eastern Bloc countries. At ISIC-11 (Kiev, 2007) the International Advisory Committee of the series decided unanimously to break with tradition and expressed their wish for future conferences to be hosted anywhere in the world. Professor Barbour's bid to host the next meeting in South Africa was met with great enthusiasm and it was then decided that ISIC-12 would take place in Stellenbosch in 2009. Than the next conferences took place in Scotland (UK) and twice in Warsaw (Poland). Now the ISIC-16 conference is held for the second time in Kazan.
The ISIC conference series is relevant to molecular inclusion phenomena in supramolecular chemistry, the life sciences, nanotechnology and advanced materials. The main objective of ISIC series is to present the frontiers of these important fields as well as bring together young and experienced scientists from all regions of the world to establish fruitful scientific collaboration at regional and global levels. Special attention will be paid to materials with useful properties, e.g. sorbents, extractants, catalysts, sensors, and biologically relevant compounds.

For historical reasons (as outlined above), this conference series has garnered a large following amongst Eastern Europeans. Now we anticipate that the majority of presenting participants will be internationally renowned researchers from Western Europe, the Americas, Asia and Australasia, as well as number of students from these regions is expected a to attend.

\section{International Seminar on Inclusion Compounds}

\begin{tabular}{|cclccl}
\hline I & 1981 & Stara Lesna, Czechoslovakia (A. Sopkova) & IX & 2003 & Novosibirsk, Russia (V. P. Fedin) \\
\hline II & 1987 & Jaszowiec, Poland (J. Lipkowski) & X & 2005 & Kazan, Russia (A. I. Konovalov) \\
\hline III & 1989 & Novosibirsk, Russia (Yu. A. Dyadin) & XI & 2007 & Kyiv, Ukraine ( V. Kalchenko) \\
\hline IV & 1991 & $\begin{array}{l}\text { Stara Lesna, Czechoslovakia } \\
\text { (A. Sopkova) }\end{array}$ & XII & 2009 & Stellenbosh, South Africa (L. Barbour) \\
\hline V & 1994 & Odessa, Ukraine (S. Andronati) & XIII & 2011 & Gierloz, Poland (K. Suwinska) \\
\hline VI & 1995 & Istanbul, Turkey (S. Akyuz, S. Erk) & XIV & 2013 & Edinburgh, Scotland (S. Dalgarno) \\
\hline VII & 1997 & $\begin{array}{l}\text { Pardubice-Sec, Czech Republic } \\
\text { (J. Kolousova) }\end{array}$ & XV & 2015 & Warsaw, Poland (K. Suwinska) \\
\hline VIII & 2001 & Popowo, Poland (K. Suwinska) & XVII & 2017 & Kazan, Russia (I. S. Antipin ) \\
\hline
\end{tabular}

This issue of Macroheterocycles is timed to the opening of ISIC-16 and contains the peerreviewed contributions submitted by participants of this symposium and papers of other authors working in the related field. 